\title{
Arduino Controlled Cooling Smart Footwear
}

\author{
A. Mohamed Nazeer ${ }^{1}$, S. Sasikala ${ }^{2}$, M. Sathish Kumar ${ }^{3}$, M. Yogeshwaran ${ }^{4}$, K. Veeramani ${ }^{5}$, R.Vigneshwaran ${ }^{6}$ \\ I,2Lecturers, Department of Electrical and Electronics Engineering, PSG Polytechnic College, Coimbatore, \\ Tamil Nadu, India \\ 3,4,5,6Student , Department of Electrical and Electronics Engineering, PSG Polytechnic College, Coimbatore, \\ Tamil Nadu, India
}

\begin{abstract}
Article Info
Volume 7, Issue 4

Page Number : 327-331

Publication Issue :

July-August-2020
\end{abstract}

\section{Article History}

Accepted : 15 Aug 2020

Published : 25 Aug 2020

\section{ABSTRACT}

This paper presents the design and fabrication of a smart footwear using peltier module. It is developed such a way that it works in various difficult weather conditions. This system works on the principle of peltier effect, which is a reciprocal of seebeck effect. This system is designed to maintain a comfortable temperature inside the footwear. This footwear may help the workers in thermal power plants, cement industries, people working in the hot weather conditions. The peltier cell consists of two surfaces of cold and hot which moves electrons between the surfaces by reversing the direction of the current. Inside the peltier's module, a $\mathrm{P}-\mathrm{N}$ junction diode like structure, made of two different metals having a high difference of electron density. The higher density diffused component in cold and hot junctions improves the performance of peltier cell.

Keywords : P-N Junction Diode, Peltier Effect, Peltier Cell

\section{INTRODUCTION}

Thermoelectric heat exchanger works with peltier effect. When the two junctions of a thermocouple are maintained at different temperatures, then a current start flowing through the loop is known as thermoelectric current. The potential difference between the junctions is called thermoelectric EMF which is of the order of a few micro-volts per degree temperature difference. When the temperature raises two different terminals (conductor or semiconductor) and it produces a voltage between two terminals is called Seebeck effect. Seebeck arranged different metals in the decreasing order of their electron density.

The thermoelectric current is directly proportional to the distance between the two metals in series. Further, the metals in the series forming the thermocouple and generates the thermal EMF. Thus, maximum thermal EMF is obtained for the SB-Bi thermocouple. The current flows from copper to iron in the junction and also the temperature observed copper to iron. It is similar to the hot coffee heat was observed in the iron 
cup. It works on a thermoelectric heat exchanger method.

When the current flow between two different metals it produces heat and cool between the two metals. The peltier effect is one of the types of thermoelectric effects. Foot wear interface consists of an internal layer, tubing, and the external layer. The internal layer is the first subcomponent of the jacket interface which must keep tight and comfortable to fit the user. The tubing is seen on the internal layer. The second sub-component of thet interface is tubing, which is thermally conductive to circulate cool water throughout the cooling vest. The tubing invests extracts heat from the body and transferred to fluid moving through it. The external layer is the final subcomponent of the vest interface used to provide insulation to the device. The external layer is used to increase thermal efficiency.

\section{PROPOSED SYSTEM}

The heat exchanger exchanges the heat and the heat is cooled in the heat sink. The principle of peltier effect works based on the thermoelectric heat exchanger. When the current flows the two di metal works on a peltier effect, one side cool and other side heat. Cooling junction heats are observed by the heat junction and the heat side is observed by the cooling junction. DHT11 Sensor works depends on compressing the vapor. The temperature is sensed by the DHT11 temperature Sensor and transmits the analog signal to the controller. The controller process the signal and it send a voltage to $5 \mathrm{~V}$ relay. The thermoelectric heat exchanger gets the voltage and it cools the footwear. Thermoelectric cooling is not very sufficient. When the sensor sense 36 degree Celsius it sense the signal and send the signal. The thermoelectric heat exchanger gets the boost voltage to $5 \mathrm{~V}$ relay. The thermoelectric heat exchanger senses the voltage and it cools the footwear. The size of the thermoelectric heat exchanger was $40 \mathrm{~mm}^{*} 40 \mathrm{~mm}^{*} 4 \mathrm{~mm}$ and it operates $0-15 \mathrm{~V}$ DC. The operating temperature -30 degrees to +40 degrees and it operates $60 \mathrm{~W}$.

\section{EXISTING SYSTEM}

When the current flows between two different metals it produces heat and cool between the two metals. The Peltier effect is one of the types of thermoelectric effects. Foot wear Interface consists of an internal layer, tubing, and the external layer. The internal layer is the first subcomponent of the jacket interface which must keep tight and comfortable to fit the user. The tubing is seen on the internal layer. The second sub-component of the vest interface is tubing, which is thermally conductive to circulate cool water throughout the cooling vest. The thermoelectric current is directly proportional to the distance between the two metals in series. Further, the metals in the series forming the thermocouple and generates the thermal EMF. Thus, maximum thermal EMF is obtained for the SB-Bi thermocouple.

\section{BLOCK DIAGRAM}

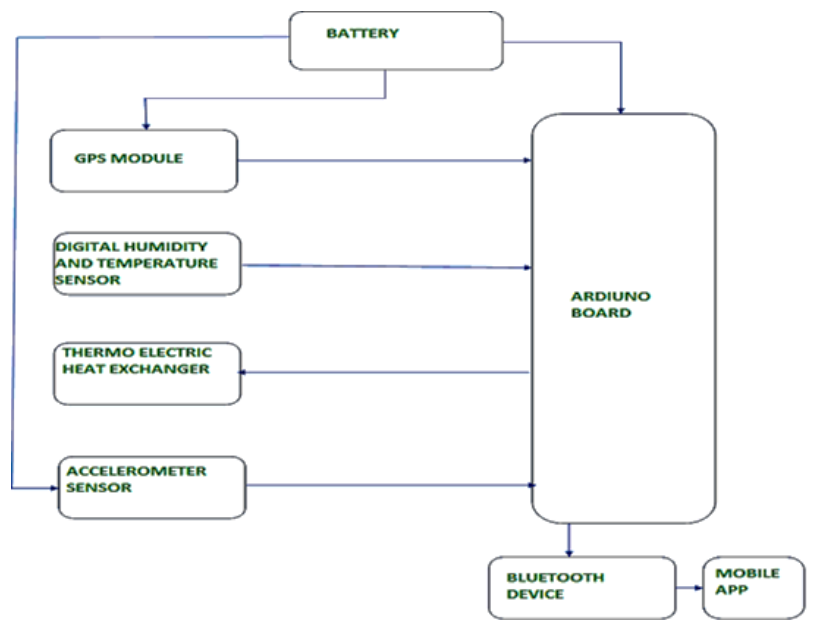




\section{CIRCUIT DIAGRAM}

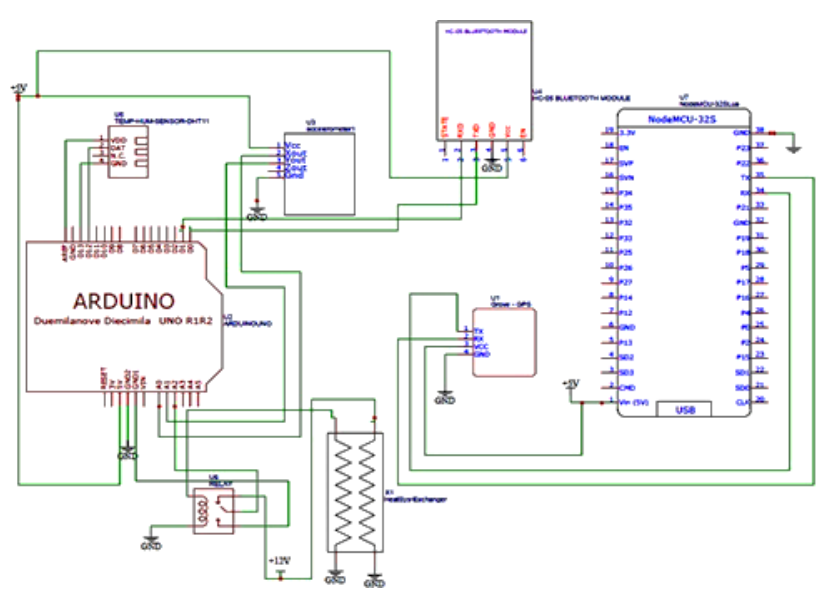

\section{HARDWARE DESCRIPTION}

\section{BATTERY:}

The $9 \mathrm{~V}$ battery is used as a source of the system. The battery is connected to the Arduino board. There are two terminals, one terminal is connected in $5 \mathrm{~V}$ and the other terminal is connected to ground. The HW battery is used in this paper.

\section{THERMO ELECTRIC HEAT EXCHANGER:}

The thermoelectric heat exchanger gets the boost voltage to the voltage controller. When the thermoelectric heat exchanger senses the voltage and it cools the footwear. The size of the thermoelectric heat exchanger is $40 \mathrm{~mm}^{*} 40 \mathrm{~mm}^{*} 4 \mathrm{~mm}$ and it operates on $0-15 \mathrm{~V}$ DC. The operating temperature is from -30 degree to +40 degree and operating power is $60 \mathrm{~W}$. The test module is also known as TEC, also called as Thermoelectric Module, Peltier Plate,Thermo electric cooler, Peltier Junction.

\section{DIGITAL HUMIDITY AND TEMPERATURE11 SENSOR:}

DHT11 Temperature \& Humidity Sensor senses the temperature and humidity levels of the surrounding and calibrated to deliver digital signal output in the form of voltage. By using the digital-signalacquisition technique, this sensor constructs with a resistive-type humidity measurement component and an NTC temperature measurement component. It connects to an ardiuno microcontroller, offering excellent performance in terms of quality, fast response, anti-interference ability, and costeffectiveness.

\section{ARDIUNO BOARD:}

The arduino board gets the signal from the DHT11 sensor and processes the signal and sends the signal and voltage to the voltage controller circuit. The DHT11 sensor is connected to analog pin and ground. The $9 \mathrm{~V}$ battery is connected to $5 \mathrm{~V}$ pin and ground pin and the analog pin is connected in voltage controller circuit. The microcontroller used is ATmega 328p AVR family microcontroller. The operating voltage of the microcontroller is $5 \mathrm{~V}$. The recommended voltage is $7-12 \mathrm{~V}$. The analog pins are A0-A5. The current rating is $40 \mathrm{~mA}$.

\section{ACCELEROMETER SENSOR:}

The rate of change of velocity of the body with respect to time is called acceleration. The accelerometer sensor is used to measure the acceleration and converts voltage pulses when exerted upon the sensor. The acceleration is identified in two- or three-dimensional movement axis-vector components so that the sum/net acceleration is calculated.

\section{GPS MODULE:}

Global Positioning System (GPS) is a navigation device consists of transmitter /receiver which locates the present position with the help of satellites. It calculates the location based on its geographical position in terms of longitude and latitude. A 
dedicated software imports the location and displays in map to identify the place of the system.

\section{SOFTWARE DESCRIPTION}

\section{ARDUINO IDE SOFTWARE MODULE:}

Arduino is an open-source platform used for building electronics projects. Arduino consists of both a physical programmable circuit board (often referred to as a microcontroller) and a piece of software, or IDE (Integrated Development Environment) that runs on a computer, used to write and upload computer code to the physical board.

IDE:

An integrated development environment (IDE) is a software application that provides comprehensive facilities to computer programmers for software development. An IDE normally consists of at least a source code editor, built in automation tools, and a debugger. Some IDEs, such as Net Beans and Eclipse, contain the necessary compiler, interpreter, or both; others, such as Sharp Develop and Lazarus, do not. IDEs are sometimes called Program Development Environments.

\section{RESULTS AND DISCUSSION}

\section{FINAL OUTPUT}

\section{SCREENSHOT OF THE STEP CALCULATION}

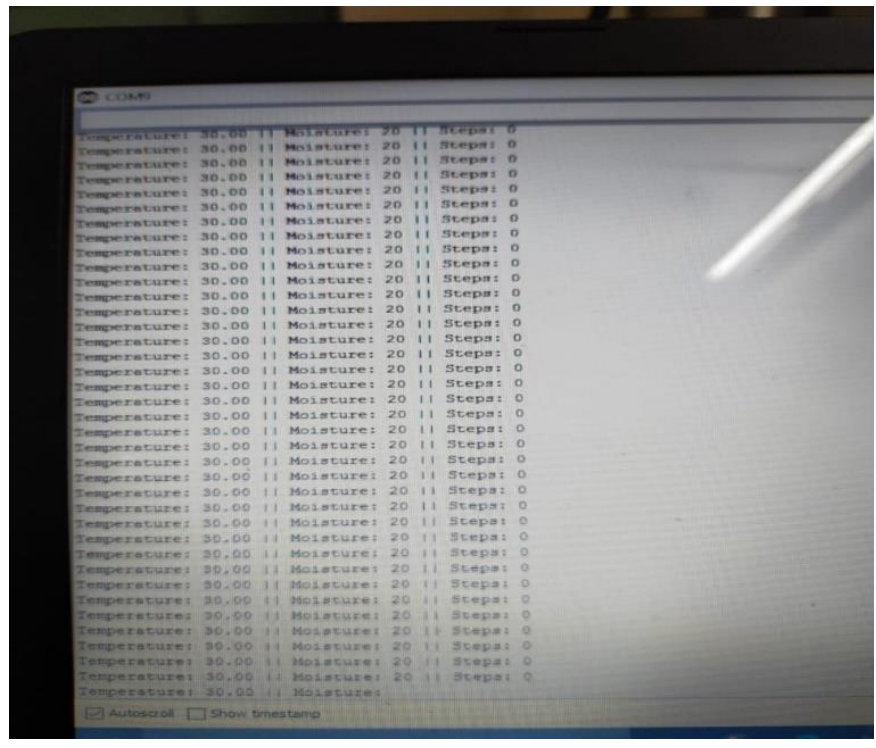

SCREENSHOT OF THE GPS TRACKING
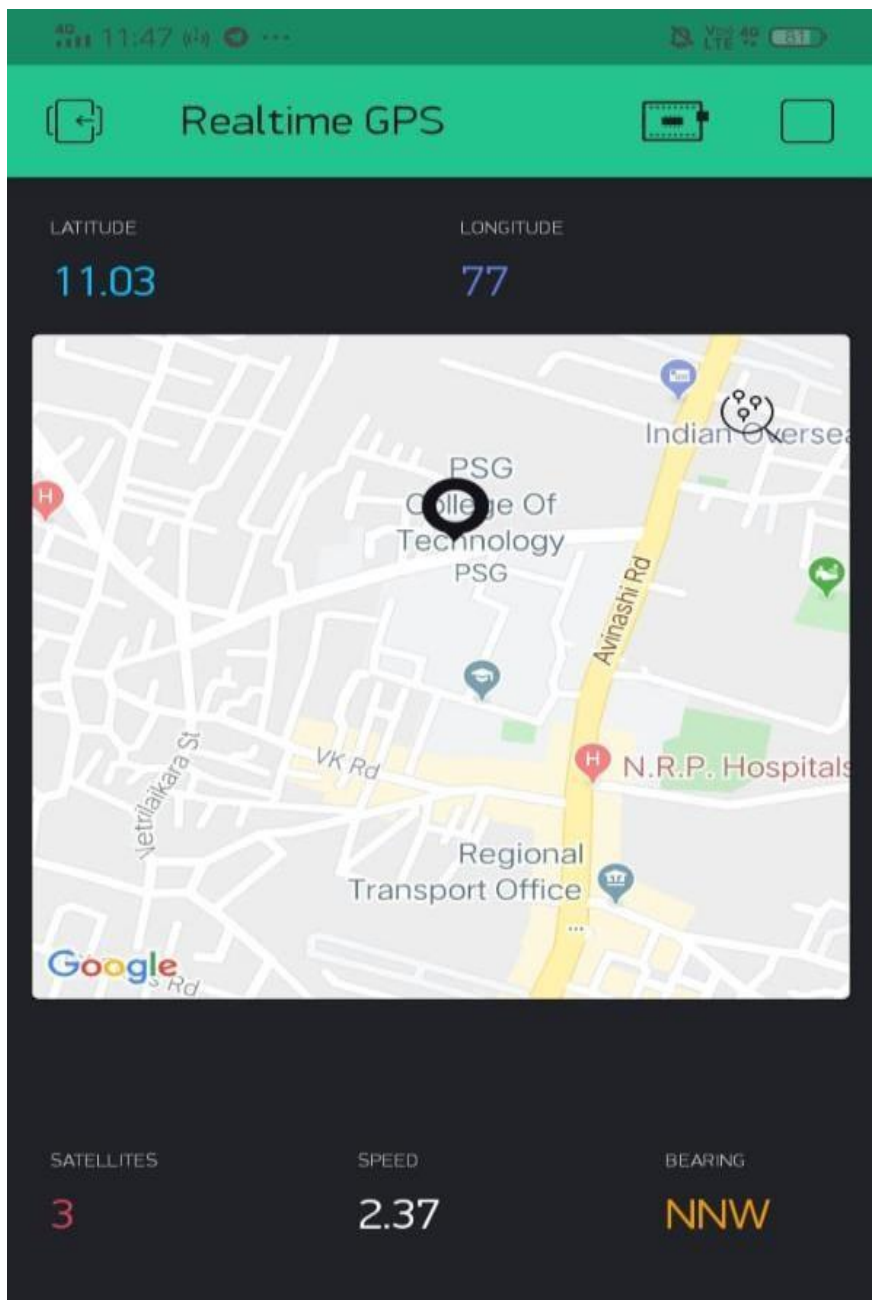


\section{OUTPUT TABLE OF THERMOELECTRIC HEAT EXCHANGER}

\begin{tabular}{|c|c|c|c|}
\hline \multirow[t]{5}{*}{ TIME VARIATION } & ROOM & PELTIER & COOLING \\
\hline & TEMPERATURE & MODULE & PAD \\
\hline & (Celsius) & OUTPUT & TEMPERATUR \\
\hline & & VOLTAGE & $\mathbf{E}$ \\
\hline & & (v) & (Celsius) \\
\hline $12.00 \mathrm{pm}$ & 30 & 6.76 & 21 \\
\hline $2.00 \mathrm{pm}$ & 28 & 4.3 & 20 \\
\hline $3.00 \mathrm{pm}$ & 27 & 3.3 & 22 \\
\hline $6.00 \mathrm{pm}$ & 25 & 2.9 & 21 \\
\hline $8.00 \mathrm{pm}$ & 24 & 2.2 & 20 \\
\hline
\end{tabular}

Footwear cooling pad maintains 21-degree Celsius temperature even higher room temperature levels. The system calculates the steps taken by the consumer in certain duration predefined by the individuals. It also indicates the location of the movement of person. The comfort with health conscious is assured.

\section{REFERENCES}

[1]. Rama Murthy.N, P.N.Sudha, "Smart Navigation System for Visually Challenged People", International Journal of Industrial Electronics and Electrical Engineering.

[2]. Ms. Rutuja Anil Shinde, Dr. S. L. Nalbalwar, Dr. Sachin Singh," Smart Shoes: Walking Towards a Better Future" International Journal of Engineering Research \& Technology.

[3]. Sayali Meshram "Wearable Smart Shoe Technology for Health Fitness using IOT" International Research Journal of Engineering and Technology.

\section{Cite this article as :}

A. Mohamed Nazeer, S. Sasikala, M. Sathish Kumar, M. Yogeshwaran, K. Veeramani , R. Vigneshwaran, "Arduino Controlled Cooling Smart Footwear", International Journal of Scientific Research in Science and Technology (IJSRST), Online ISSN : 2395-602X, Print ISSN : 2395-6011, Volume 7 Issue 4, pp. 327-331, July-August 2020. Available at doi $\quad$ : https://doi.org/10.32628/IJSRST207480 Journal URL : http://ijsrst.com/IJSRST207480 